\title{
Smoking behavior of adolescents and their view towards government's ban on smoking in public places in Kathmandu
}

\author{
Dahal $S,{ }^{1 *}$ Subedi RK, ${ }^{1}$ Maharjan $S,{ }^{2}$ Maharjan $J^{3}$ \\ ${ }^{1} M P H$, Central Institute of Science and Technology, Kathmandu, Nepal, \\ ${ }^{2}$ MA, Tribhuwan University, Nepal, ${ }^{3} B P H$, Lumanti support group for shelter Nepal
}

*Corresponding Author:

Dahal S MPH, Lecturer, Central Institute of Science and Technology (CiST), Sangam Chowk, New Baneshwor, Kathmandu-34, Nepal.

Email address: sushdahal@gmail.com

\begin{abstract}
Background: Several studies have reported that different forms of tobacco use are high in Nepal. However, information about factors affecting the cigarette smoking behavior of adolescents is inadequate. The objective of this study was to explore the cigarette smoking behavior of adolescents and to determine its association with their views towards cigarette smoking.
\end{abstract}

Methods: A cross-sectional study was conducted among 394 adolescent students by using questionnaire method in 3 randomly selected colleges of Kathmandu district, Nepal. Data were analyzed by using bivariate and binary logistic regression analysis.

Results: The study found that $22 \%$ of the students were ever smokers. Higher percentage of students receiving more amount of pocket money, having poor academic performance, having frequent dispute with teachers, having alcohol using and smoker family members were ever smokers. Multivariate analysis showed that students were more likely to be current smokers if they have positive views towards smoking and were less likely to be current smokers if they have negative view towards smoking $(\mathrm{p}<0.01)$.

Conclusion: Reasons for smoking are many that create challenges for smoking control programs. Changing the views and imagery of adolescents' towards cigarette smoking should also be considered while designing such programs.

Keywords: Adolescents, Ban, Nepal, Smoking, Tobacco, View

\section{Background}

Tobacco epidemic is considered as one of the biggest public health threats the world has ever faced, killing nearly six million people a year. ${ }^{1}$ Cigarette smoking is a major cause of coronary heart disease, chronic obstructive pulmonary disease, and lung cancer. ${ }^{2}$ Global burden of diseases study 2010, has revealed that blood pressure, is the biggest risk factor for diseases followed by tobacco, alcohol and poor 
diet. $^{3}$ The same study revealed that smoking is the third largest factor for death globally. ${ }^{4}$

The risk of injury or death during adolescence is 2-3 times that of childhood mainly due to increase in risky behaviors like drinking, speed driving, drug-taking, smoking and unprotected sex. ${ }^{5}$ Among urban young people, smoking is often perceived as symbol of independence and a modern fashion. ${ }^{6}$ College students are particularly vulnerable towards this perception as they leave school and enter into the world of adulthood and will be seeking avenues to express their maturity, independence and fashion by emulating the smoking habit which is considered as adult behavior. ${ }^{7}$ Attitude of adolescents towards smokers reflects their view towards smoking and determines their current or future smoking behavior. ${ }^{8}$ According to Global Youth Tobacco Survey (GYTS) 2011, among Nepalese youth aged 13-15 years, the prevalence of current tobacco use is $20.4 \%$ and the prevalence of current cigarette use is $3.1 \%{ }^{9}$ The National Demographic Health Survey (NDHS) conducted in $2011^{10}$, revealed that tobacco use is more common among Nepalese men than women (52\% compared with 13\%). Thirty percent of men and $9 \%$ of women smoke cigarette in Nepal. The percentages of men and women aged 15-19 years who smoke cigarette are $13.1 \%$ and $0.5 \%$ respectively. In both men and women, tobacco use is more common among older ones, those living in rural areas, those with no education and those in the lowest wealth quintile. ${ }^{10}$

In Nepal, with the Tobacco Control and Regulatory Act$2011^{11}$ coming into effect, ban on smoking in public places has been enforced. Government offices, corporations, educational institutions, libraries, airports, public vehicles, orphanages, childcare centers, cinema halls, homes for the elderly, cultural centers, children's gardens, hotels, restaurants, resorts, girls' and boys' hostels, department stores, religious sites and industries have been designated as no smoking zones. The ban covers sale of tobacco products and cigarette sticks within a 100-metre radius of educational and health institutions, children's homes, child care centers and home for elders. According to the act, those smoking in public places will be fined up to Nepalese Rupees (NRs) 100 and anyone selling tobacco products to persons under the age of 18 years and pregnant women will be fined up to NRs 10,000 .

In Nepal, many studies have been done regarding tobacco use, but information about cigarette smoking and its correlates particularly among higher secondary level students in urban areas is inadequate. Moreover, previous studies including GYTS have not explored factors associated with cigarette smoking and views towards smoking among higher secondary level students in urban areas. Information about smoking habit of adolescent students, factors affecting the onset of cigarette smoking, and their views towards smoking will be helpful to researchers and policy makers in designing smoking prevention programs particularly for adolescent men and women in urban areas.

\section{Methods}

An observational cross-sectional study was done among 394 students studying in the ' $10+2$ ' colleges of Kathmandu district, Nepal from March to August, 2013. In Nepal, 10 +2 level studies mean higher secondary studies (i.e. grade 11 and grade 12) taught at the college after completion of School Leaving Certificate (SLC) level. Many students from different parts of Nepal, after having passed SLC level prefer going to Kathmandu, the capital city for $10+2$ level studies. In this context, it is imperative to study adolescents' behavior and vulnerability to different risky behaviors like cigarette smoking.

Ethical approval was taken from Institutional Review Committee of University Grants

Commission (UGC), Nepal. For selecting colleges, at first the list of 10+2 colleges of Kathmandu district under Higher Secondary Education Board (HSEB) of Nepal was obtained that yielded a total of 56 colleges. From among 50 colleges that gave consent for study, 3 were randomly selected. In each college, grade 11 and grade 12 students were selected from attendance sheet using probability proportionate to size (PPS) method. Informed consent was taken from the students before administering the questionnaire. The selected students were shared the objective of the study, explained the questionnaire, assured confidentiality of their information and administered the questionnaire individually. During data collection, different measures were taken to ensure students about the anonymity of their information e.g. teachers were not present during information collection, name of students was not taken, and the respondents were asked to fill the questionnaire by themselves.

The tools used in GYTS $2002^{12}$, NDHS $2011^{10}$ and other studies ${ }^{13,14}$ were referred to for preparing the questionnaire. The prepared questionnaire was further pretested in a $10+2$ college in another district (Bhaktapur) near to Kathmandu. 
The questionnaire was designed first in English language and was translated to Nepali for data collection which was then again translated back to English for analysis and report writing. Overall response rate for the study was $100 \%$ and with $85.3 \%$ complete response rate.

Data was entered and analyzed using IBM SPSS 20 for windows. Smoking status of students was categorized as ever smokers and never smokers which is similar to the previously done study in Nepal. ${ }^{15}$ Ever smokers included those students who had ever smoked (even a single puff) and never smokers included those students who never smoked cigarette (even a single puff) in his/her life time. Among ever smokers, those who smoked cigarette at least once in the past 30 days prior to data collection were considered as the current smokers ${ }^{7,15}$.The Chi-squared test statistics was calculated to measure association between attitude towards smokers and current smoking behavior. The Unadjusted Odds Ratio (OR) and their 95\% Confidence Interval (CI) were calculated by bivariate analysis. Further Adjusted Odds Ratios (AOR) and their 95\% CI were also calculated from logistic regression analysis after adjusting for sex, smoking by family member in house and alcohol use by family member in house. Different predictors of current smoking were calculated so that the results would be useful for planning further interventions.

\section{Results}

\section{Demographic information}

Table 1 explains the demographic characteristics of 394 students of whom $66.8 \%$ were male, $73.4 \%$ were of age group 16-17 years. The mean age of respondents was 16.77 years and the range was 13-22 years. Around one third of respondents had smoking (34\%) and alcohol using (38\%) family members. The median amount of pocket money per month provided to respondents was NRs 2000 and the money provided ranged from NRs 100 to NRs 20,000. Around 63\% of respondents perceived that their academic performance was good, $13.7 \%$ never liked to do risky activities (e.g. high speed biking, late night partying, carrying weapons etc.) and $70.6 \%$ never had dispute with teachers. Higher percentage of students were ever smokers if they were males (28.1\%), had family member who smoke cigarette (34.3\%), had family member who used alcohol (37.2\%), were provided monthly pocket money of more than NRs 5000 (45.2\%), perceived their academic performance as poor $(55.6 \%)$, always liked to do risky activities (33.9\%) and had frequent dispute with teachers $(62.5 \%)$.
Table 1. Socio-demographic information of the respondents

\begin{tabular}{|c|c|c|c|}
\hline Variables & $\begin{array}{c}\text { Ever } \\
\text { smokers (\%*) }\end{array}$ & $\begin{array}{c}\text { Never } \\
\text { smokers }\left(\%{ }^{*}\right)\end{array}$ & $\begin{array}{l}\text { Total } \\
\left(\%{ }^{\sharp}\right) \\
\end{array}$ \\
\hline \multicolumn{4}{|l|}{ Sex $(n=394)$} \\
\hline Male & $74(28.1)$ & $189(71.9)$ & $263(66.8)$ \\
\hline Female & $14(10.7)$ & $117(89.3)$ & 131(33.2) \\
\hline \multicolumn{4}{|l|}{ Age $(n=394)$} \\
\hline 13 to 15 years & $6(23.1)$ & $20(76.9)$ & $26(6.6)$ \\
\hline 16-17 years & $54(18.7)$ & $235(81.3)$ & $289(73.4)$ \\
\hline 18 to 19 years & $28(35.9)$ & $50(64.1)$ & $78(19.8)$ \\
\hline More than or equal to 20 years & $0(0)$ & $1(100)$ & $1(0.3)$ \\
\hline \multicolumn{4}{|l|}{ Family type $(n=393)$} \\
\hline Nuclear & $51(22.9)$ & $172(77.1)$ & $223(56.7)$ \\
\hline Joint/Extended & $37(21.8)$ & $133(78.2)$ & $170(43.3)$ \\
\hline \multicolumn{4}{|c|}{ Smoking family members $(n=394)$} \\
\hline Yes & $46(34.3)$ & $88(65.7)$ & $134(34)$ \\
\hline No & $42(16.2)$ & $218(83.8)$ & $260(66)$ \\
\hline \multicolumn{4}{|c|}{ Alcohol use by family members $(\mathrm{n}=382)$} \\
\hline Yes & $54(37.2)$ & $91(62.8)$ & $145(38)$ \\
\hline No & $33(13.9)$ & $204(86.1)$ & $237(62)$ \\
\hline \multicolumn{4}{|c|}{ Pocket money provided (NRs per month) (n=336) } \\
\hline Less than or equal to NRs 2500 & $30(14.9)$ & $172(85.1)$ & $202(60.1)$ \\
\hline $00-5000$ & $37(35.9)$ & $66(64.1)$ & $103(30.7)$ \\
\hline More than NRs 5000 & $14(45.2)$ & $17(54.8)$ & $31(9.2)$ \\
\hline \multicolumn{4}{|c|}{ Perceived level of academic performance $(n=394)$} \\
\hline Good & $39(15.6)$ & $211(84.4)$ & $250(63.4)$ \\
\hline Satisfactory & $44(32.6)$ & $91(67.4)$ & $135(34.3)$ \\
\hline Poor & $5(55.6)$ & $4(44.4)$ & $9(2.3)$ \\
\hline \multicolumn{4}{|c|}{ Like to do risky activities $(n=394)$} \\
\hline Yes, always & $37(33.9)$ & $72(66.1)$ & $109(27.7)$ \\
\hline Yes, sometimes & $46(19.9)$ & $185(80.1)$ & $231(58.6)$ \\
\hline Never & $5(9.3)$ & $49(90.7)$ & $54(13.7)$ \\
\hline \multicolumn{4}{|c|}{ Dispute with the teacher $(n=394)$} \\
\hline Yes, many times & $20(62.5)$ & $12(37.5)$ & $32(8.1)$ \\
\hline Yes, sometimes & $31(36.9)$ & $53(63.1)$ & 84 (21.3) \\
\hline Never & 37 (13.3) & $241(86.7)$ & $278(70.6)$ \\
\hline
\end{tabular}

*Percentage of row total

\#Percentage of total ' $n$ 'for each variable

\section{Cigarette smoking habit}

The median and modal age when ever smokers first smoked cigarette was 15 years and the range of age when ever smokers smoked their first cigarette was 7- 19 years. Table 2 explains that, out of total respondents $22 \%$ were ever smokers and $17 \%$ were current smokers. $11.7 \%$ used other forms of tobacco. Around half of the current smokers had smoked more than 100 sticks of cigarette till the day of interview and $28.4 \%$ had smoked all day in last 30 days prior to interview. Among current smokers, common reasons behind smoking were 'smoking by friends' $(68.6 \%)$, followed by 'smoking in film or music by favorite artists' $(23.9 \%)$. Majority of current smokers $(88.1 \%)$ bought cigarette from shop and the most common place of smoking were unspecified places outside school premises (38.8\%) followed by café/hotel/ 
restaurants $(31.3 \%)$.

Table 2. Cigarette smoking habit of the respondents

\begin{tabular}{|c|c|c|}
\hline $\begin{array}{c}\text { Smoking related } \\
\text { characteristics of respondents }\end{array}$ & Frequency & Percent \\
\hline \multicolumn{3}{|l|}{ Ever smoking $(n=394)$} \\
\hline Yes & 88 & 22 \\
\hline No & 306 & 78 \\
\hline \multicolumn{3}{|l|}{ Current smoking $(n=394)$} \\
\hline Yes & 67 & 17 \\
\hline $\begin{array}{l}\text { No } \\
\text { Use of other tobacco products }(n=386)\end{array}$ & 327 & 83 \\
\hline $\begin{array}{l}\text { Yes } \\
\text { No }\end{array}$ & $\begin{array}{l}45 \\
341\end{array}$ & $\begin{array}{l}11.7 \\
88.3\end{array}$ \\
\hline \multicolumn{3}{|c|}{ Number of cigarettes smoked (among current smokers) $(n=67)$} \\
\hline Few puffs & 20 & 29.9 \\
\hline 1-19 stick & 7 & 10.4 \\
\hline 20-100 stick & 10 & 14.9 \\
\hline More than 100 stick & 30 & 44.8 \\
\hline \multicolumn{3}{|c|}{ Days smoked in last 30 days (among current smokers) $(n=67)$} \\
\hline 1-2 days & 17 & 25.4 \\
\hline 3-5 days & 7 & 10.4 \\
\hline 6-9 days & 15 & 22.4 \\
\hline 10-19 days & 9 & 13.4 \\
\hline 20-29 days & 0 & 0 \\
\hline All days & 19 & 28.4 \\
\hline \multicolumn{3}{|c|}{ Reasons behind smoking (among current smokers) $(n=67)$} \\
\hline Smoking in film/music by favorite artists & 16 & 23.9 \\
\hline Smoking by father/mother & 5 & 7.4 \\
\hline Study related stress & 6 & 9 \\
\hline Relation related stress & 7 & 10.4 \\
\hline \multicolumn{3}{|c|}{ Method of cigarette acquisition (among current smokers) $(n=67)$} \\
\hline Buying from shop & 59 & 88.1 \\
\hline Sent others to buy & 4 & 6 \\
\hline Borrowed from other & 1 & 1.5 \\
\hline Other & 3 & 4.5 \\
\hline \multicolumn{3}{|c|}{ Most common place of smoking (among current smokers) $(n=67)$} \\
\hline Home & 5 & 7.4 \\
\hline School premises & 1 & 1.5 \\
\hline Unspecified places outside school premises & 26 & 38.8 \\
\hline Friend's place & 8 & 11.9 \\
\hline Café/hotel/restaurants & 21 & 31.3 \\
\hline Others & 6 & 9 \\
\hline
\end{tabular}

"Views towards smoking" and "smoking behavior"

Different views like "smoking is common among friends", "smoking is usual in this age", "smokers are more sociable", "smokers look cool”, "A boy who smokes is a real man', 'A girl who smokes is an intelligent woman' were significantly associated with current smoking status of respondents at $95 \%$ CI with $\mathrm{p}<0.01$. Logistic regression was used to calculate Adjusted Odds Ratio (AOR) to find out association between different views and current smoking status after adjusting for three variables 'sex', 'smoking by family members' and 'alcohol use by family members' showed that those who agreed the view 'smoking is common among friends' ( $\mathrm{AOR}=5.14, \mathrm{CI}: 2.53$ to 10.40); 'smoking is usual in this age' ( $\mathrm{AOR}=3.88, \mathrm{CI}: 2.09$ to 7.18$)$; 'smokers are sociable and have many friends' $(\mathrm{AOR}=3.36, \mathrm{CI}: 1.69$ to 6.66); 'smokers look cool' ( $\mathrm{AOR}=3.15, \mathrm{CI}$ : 1.62 to 6.09 ); 'A boy who smokes is a real man' $(\mathrm{AOR}=4.74, \mathrm{CI}: 2.16$ to 10.39); 'A girl who smokes is an intelligent woman' $(\mathrm{AOR}=5.28, \mathrm{CI}: 2.29$ to 12.14$)$; 'I don't mind if my friends smoke' (AOR=2.76, CI: 1.52 to 5.03$)$ are more likely to be current smokers compared to those who disagree the views. Similarly respondents who agree the views: 'I don't like if my friends smoke' (AOR=0.3, CI: 0.16 to 0.57$)$; 'It's foolish to do smoking by somebody of my age' (AOR=0.35, CI: 0.19 to 0.65 ) are less likely to be current smokers compared to those who disagree (Table 3 ).

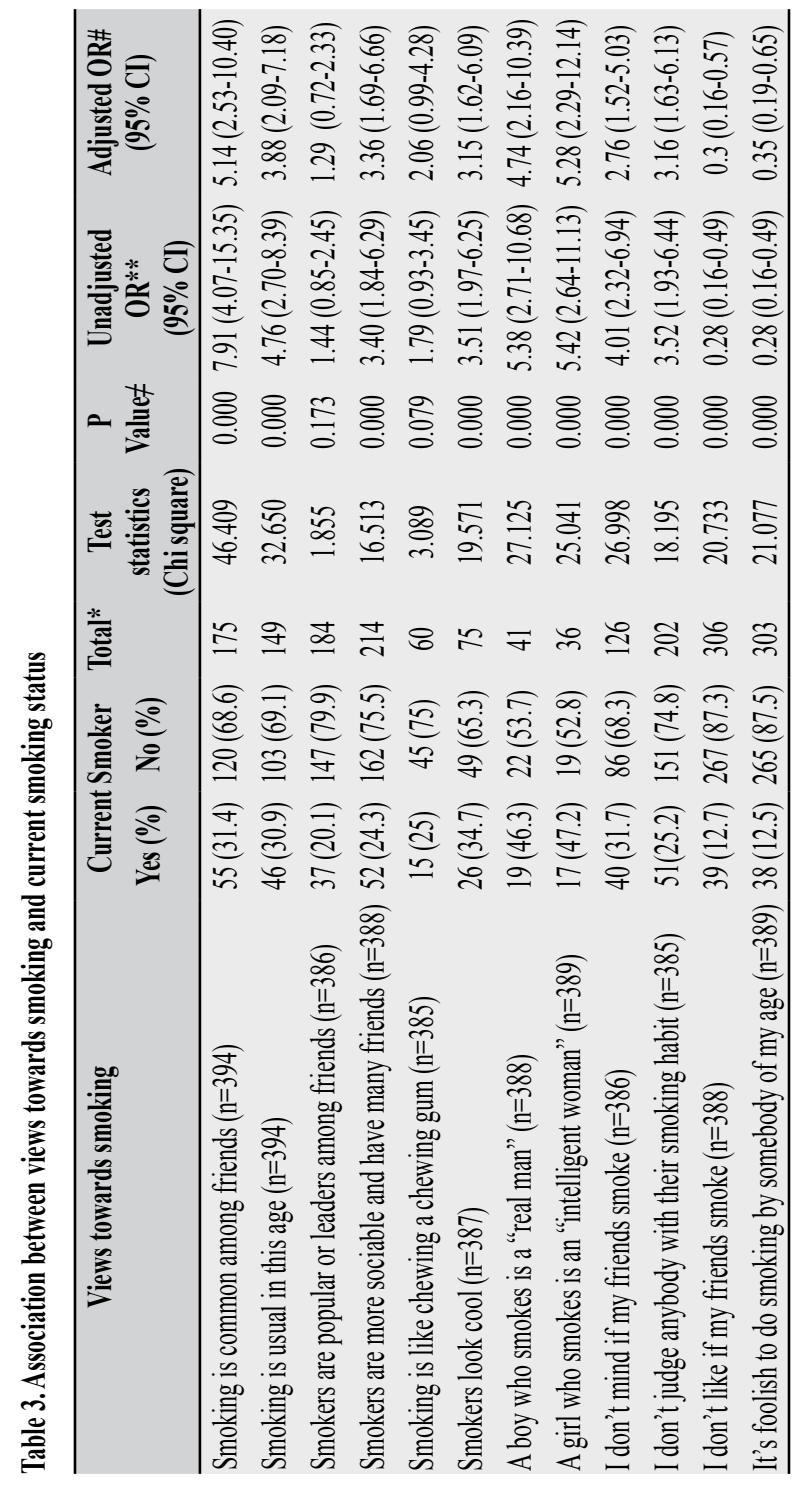

*Those who agreed the views

$\neq$ Chi-square test applied at $1 \mathrm{df}$

$\mathrm{OR}=$ Odds Ratio; $\mathrm{CI}=$ Confidence Interval. The $95 \% \mathrm{CI}$ that does not include 1 is significant at $\mathrm{P}<0.05$.

**Unadjusted OR calculated using bivariate analysis 
\#Adjusted Odds Ratio (AOR); adjusted for sex, alcohol using and smoker family members in the house

\section{Image towards smoker artists in movies}

Around $38 \%$ of respondents viewed smoker artists as stylish. However, $10.6 \%$ of respondents viewed smoker artists as unintelligent/foolish (Figure 1).

\section{Image towards smoker artist in movies}

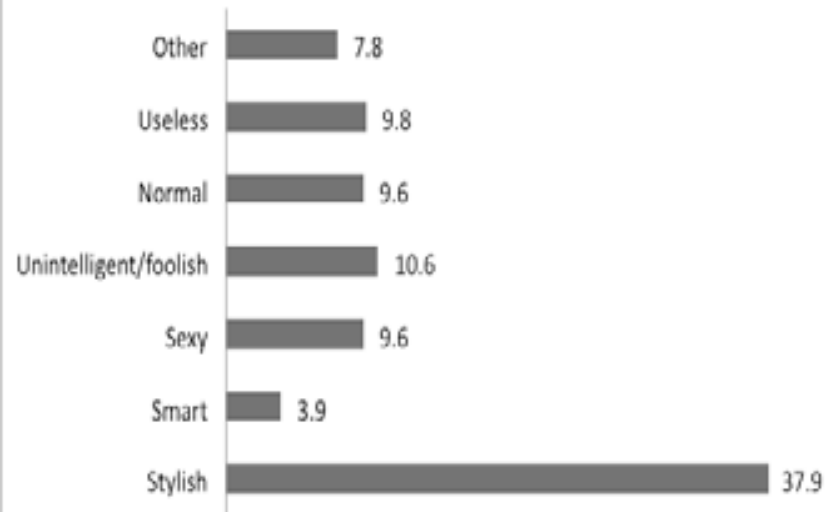

Figure 1. Image towards smoker artist in movies

\section{Discussion}

Smoking is a form of learned deviational behavior among adolescents. ${ }^{16}$ Many people are likely to initiate smoking primarily during adolescence. ${ }^{17}$ Studies among school-age and college students report that most students begin smoking between 13-16 years of age and that initiation age ranges between $15-18$ years. ${ }^{18}$ In this study also, the median age at first smoking was 15 years. Currently the shift in initiation of tobacco use below 18 years is a threat to tobacco epidemic [19]. Early initiation of tobacco use and cigarette smoking causes adverse health effects among young people. ${ }^{20}$

Global Youth Tobacco Survey 2011 that analyzed 1,602 students of $13-15$ years age ${ }^{21}$ found that $10 \%$ of the students were ever cigarette smokers and 3.1\% were current smokers. NDHS, a nationally representative survey, 2011 showed that the percentages of men and women aged 15-19 years who smoke cigarette were $13.1 \%$ and $0.5 \%$ respectively. ${ }^{10}$ According to a study done among college students in Kathmandu valley ${ }^{22}, 70 \%$ of students were current cigarette smokers of whom $78 \%$ were established smokers. Prevalence of ever smoking was $34.2 \%$ and current smoking was $17 \%$ among college going youths in Western Nepal. ${ }^{7}$ In our study, $22 \%$ of the respondents were ever cigarette smokers and $17 \%$ were current smokers. Differences in age of study population, sample size, study site might also have affected the difference in data on current and ever smoking in above different studies.

In Nepal, $30 \%$ of men and $9 \%$ of women smoke cigarettes and for both groups tobacco use is more common among older ones. ${ }^{10}$ For many smokers in Nepal, smoking habit is handed down from the ancestors. ${ }^{23}$ According to a study done in Massachusetts, parents were overwhelmingly the primary source of tobacco for youths at the onset of smoking where half smoked cigarettes in the ashtrays of relatives were a common source. ${ }^{24}$ Frequent exposures to people smoking and alcohol drinking determine adolescents smoking habit. ${ }^{25}$ In our study it was found that out of total students who had alcohol consuming and smoker family member at home $37.2 \%$ and $34.3 \%$ were ever smokers, respectively. So, smoking prevention programs among adolescents should consider family level interventions like counseling parents to avoid smoking and alcohol consumption at home. Similarly, antenatal and child health clinics can also be used to inform prospective parents about the harms of introducing smoking and alcohol consuming behavior to children at home. ${ }^{26}$

Emotional and behavioral factors as well as peer group factors are identified as important determinants of smoking initiation among adolescents. ${ }^{25}$ A study previously done in $\mathrm{Nepal}^{27}$ showed, influence from friends (52.5\%) and influence of parents or senior family members who smoke $(18.8 \%)$ as the major reasons for tobacco smoking. In our study also, cigarette smoking by friends $(68.6 \%)$ was the major reason behind smoking among current smokers followed by, cigarette smoking by favorite film/music artists $(23.9 \%)$ and relation related stress (10.4\%).

Similar to previous studies that showed, lower academic grades and getting higher disposable monetary allowance from family as important risk factors for adolescents' smoking $^{16,26}$; this study found that $15.6 \%$ and $55.6 \%$ of students who perceived their academic performance as good and as poor respectively were ever smokers. Similarly, $45.2 \%$ of those who received more than NRs 5000 for pocket money were ever smokers compared to $14.9 \%$ of those who received less than or equal to NRs 2500. Other important variables found in this study were willingness to do risky activities (e.g. high speed biking, late night partying, carrying weapons etc.) and dispute with teacher. Higher percentage of students who always liked to do risky activities (33.9\%) were ever smokers compared to $9.3 \%$ of those who never liked to do risky works; and $62.5 \%$ of students who frequently had dispute with teachers were ever smokers compared to $13.3 \%$ of those who never had dispute with teachers.

According to a study by McCool et al., adolescents who were susceptible to smoking were significantly more likely to acknowledge the positive image stereotypes (sexy, stylish) of smokers compared to non-susceptible students. ${ }^{13}$ The young person who accepts an offer of cigarettes gets greater acceptance from smoking peers as well as identifies himself as more 'tough', cool, mature and more adventurous that his/her nonsmoking friend. ${ }^{28}$ Smoking functions as a sign of independence from adult authority and of maturity 
among adolescents. ${ }^{28}$

Youth who smoke and are susceptible to smoke in the future tend to overestimate the prevalence of smoking more than do non-smoking youth. ${ }^{29}$ In our study, views that "smoking is common among friends" and "smoking is usual in this age" were significantly associated with students' current smoking status at $\mathrm{p}<0.01$. Other views, like "smokers are more sociable and have many friends", "smokers look cool", "a boy who smokes is a real man", "a girl who smokes is an intelligent woman" were also significantly associated with current smoking status at $\mathrm{p}<0.01$. A study in China showed that $25.7 \%$ of the ever smokers were of the view that it is unfriendly to refuse when someone offered a cigarette. The same research showed $33.9 \%$ of the ever smokers were of the view that smoking is an easy way to approach other person. ${ }^{30}$ Central role of cigarette smoking and alcohol use was found in the peer socialization and relationship building among college students in Vietnam as well. ${ }^{31}$ In China, the major reasons behind smoking were belief that one looks elegant while smoking and trying to be fashionable. ${ }^{32}$ This type of view was reflected among students in our study also. More than one third of students $(37.9 \%)$ were of view that smokers in movies are 'stylish' which reflects their positive image towards smokers in general. Positive images and positive attitude towards smokers may lead to acceptance of smoking as normal part of everyday life among experimenters, never smokers and current smokers also leaving them susceptible to adopting or continuing cigarette smoking in later life. ${ }^{33}$ Movies and music have important effect on shaping the mindset of students. In India in 2003, $62 \%$ of the films in which there were smoking scenes were judged as neutral. ${ }^{34}$ This may lead adolescents to conceive cigarette smoking as normal behavior.

In Nepal, tobacco product control and regulatory act 2011 that came into force has major features like: smoking and tobacco use ban in public places, work places and public transportation; sales ban to children under 18 years and pregnant women,; sales ban within the span of 100 meter distance from educational and health institutions, child welfare homes, child care centers, elders' care home etc. ${ }^{11}$ Despite the enforcement of regulation, our study found that $88.1 \%$ of the respondents bought cigarette from shops by themselves. Similarly, common places of smoking were found to be café/hotel/restaurants $(31.3 \%)$, and other unspecified places outside school (38.8\%). Higher percent of adolescents acquiring cigarette from shop and public places like café/hotel/restaurants being common place of smoking show that tobacco product control and regulatory act 2011 is not strictly implemented in Nepal. Exploration of reasons for the gap between current legal provision and cigarette smoking practice can be area of further research interest.

\section{Conclusion}

This study has focused on adolescent students' smoking behavior and their views towards smoking. The study has found that there is difference in current smoking status of those with positive and negative views towards smoking. Our study suggests that smoking control programs should not only focus on informing about effects of smoking but also work to discourage positive imagery towards smoking. Efforts should also be made to make them believe: "smoking is not common in their age" and, "it is not the normal part of everyday life". Similarly, this study also recommends the need of family and college level interventions. Guardians also need to keep a careful watch on their children while allotting pocket money. ${ }^{26}$ Adolescents with poor academic performance, frequently having dispute with their teachers and, those whose friends do cigarette smoking need to be monitored regularly.

\section{Competing interests}

The authors declare that they have no competing interests.

\section{Acknowledgements}

We are heartily thankful to all the colleges that gave permission for study. We acknowledge all the students who participated in the study. We would like to thank the data enumerators: Mr. Madhav KC and Mr. Saurav Chandra Acharya. The authors acknowledge University Grants Commission (UGC), Nepal for funding this study.

\section{References}

1. WHO. Tobacco free initiative. [Accessed on 9th April, 2014]; Available from: http://www.who.int/tobacco/ economics/en/.

2. Burns DM. Tobacco-related diseases. Semin Oncol Nurs. 2003; 19(4):244-249.

3. Horton R. GBD 2010: understanding disease, injury, and risk. Lancet. 2012; 380(9859).

4. Freeman MK, Sanman E, Cowling $\mathrm{K}$, et al. Concentrating risk: a systematic analysis of the global smoking epidemic.Lancet; 2013.

5. Pharo H, Sim C, Graham M, et al. Risky business: executive function, personality, and reckless behavior during adolescence and emerging adulthood. Behav Neurosci. 2011; 125(6):970.

6. MoHP. Brief profile on tobacco control in Nepal. [Accessed on 9th April, 2014]; Available from: http:// apps.who.int/fctc/reporting/party_reports/nepal_2012 annex 2 tobacco profile.pdf.

7. Binu VS, Subba SH, Menezes RG, et al. Smoking among Nepali youth--prevalence and predictors. Asian 
Pac J Cancer Prev. 2010;11(1): 221-6.

8. Piko B. Smoking in adolescence do attitudes matter? Addict Behav. 2001; 26(2):201-17.

9. WHO SEARO. Global Youth Tobacco Survey. 2011. Available from: http://www.searo.who.int/entity/ noncommunicable diseases/data/nep gyts fs 2011. $p d f$

10. MoHP, New ERA, and ICF International Inc. Nepal Demographic and Health Survey 2011. Ministry of Health and Population, New ERA, and ICF International, Calverton, Maryland: Kathmandu, Nepal;2012.

11. WHO. Tobacco Product (Control and Regulatory) Act, 2011; unofficial translation. [Accessed on 9th April, 2014; Available from: http://www.who.int/fctc/ reporting/party reports/nepal 2012 annex 1 tobacco product_control_regulatory act_2011.pdf.

12. Core questions, Global Youth Tobacco Survey. 2002. [Accessed on 9th April, 2014; Available from: http:// www.biomedcentral.com/content/supplementary/14712458-6-169-s1.pdf.

13. McCool JP, Cameron L, and Petrie K. Stereotyping the smoker: adolescents' appraisals of smokers in film. Tob Control. 2004; 13(3):308-314.

14. Cox RG, Zhang L, Johnson WD, et al. Academic performance and substance use: findings from a state survey of public high school students. J Sch Health. 2007; 77(3):109-115.

15. Aryal R, Lohani S. Perceived risk of cigarette smoking among college students. J Nepal Health Res Counc. 2011.

16. Jung M, Chung D. Evidence of social contextual effects on adolescent smoking in South Korea. Asia Pac J Public Health. 2013; 25(3):260-270.

17. U.S. Department of Health and Human Services: Preventing tobacco use among youth and young adults: A report of the Surgeon General. Department of Health and Human Services, Centers for Disease Control and Prevention: Atlanta: U.S. 2012.

18. Sreeramareddy CT, Kishore PV, Paudel J, et al. Prevalence and correlates of tobacco use amongst junior collegiates in twin cities of western Nepal: a cross-sectional, questionnaire-based survey.BMC Public Health. 2008; 8(1):97.

19. WHO: WHO report on the global tobacco epidemic. WHO: Geneva, Switzerland; 2008.

20. U.S. Department of Health and Human Services: Preventing tobacco use among young people: A report of the Surgeon General. 1994.

21. MoHP: Nepal 2011 country report Global Youth Tobacco Survey (GYTS) \& Nepal 2011 country report
Global School Personnel Survey (GSPS). Ministry of Health and Population, National Health Education, Information and communication Centre: Kathmandu. 2012. Available from: http://nheicc.gov.np/userfiles/ file/tcp/GYTS-GSPS-Rpeort-2011.pdf

22. Aryal UR, Deuba K, Subedi A, et al. Prevalence and Determinants of Cigarette Smoking among the College Students of Kathmandu Valley. Asian Journal of Medical Sciences. 2011; 1(2):53-58.

23. MoHP: The national anti-tobacco communication campaign strategy for Nepal. [Accessed on 22 ${ }^{\text {nd }}$ April, 2014; Available from: http://www.mohp.gov.np/ english/files/new_publications/9-3-Tobacco-ControlAct.pdf

24. DiFranza JR, Coleman M. Sources of tobacco for youths in communities with strong enforcement of youth access laws. Tob Control. 2001. 10(4):323-328.

25. Weiss JW, Mouttapa M, Cen S, et al. Longitudinal effects of hostility, depression, and bullying on adolescent smoking initiation. J Adolesc Health. 2011; 48(6):591-596.

26. Das S, Ghosh M, Sarkar M, et al. Adolescents Speak: Why do we Smoke? J Trop Pediatr. 2011; 57(6).

27. Karki YB, Pant KD, Pande BR. A Study on the Economics of Tobacco in Nepal. 2003.

28. Mcalister AL, Perry C, Maccoby N. Adolescent smoking: onset and prevention. Am AcadPediatrics. 1979; 63(650).

29. Page RM, Huong NT, Chi HK, et al. Social normative beliefs about smoking among Vietnamese adolescents. Asia Pac J Public Health. 2012;24(68).

30. Zhang L, Wang W, Zhao Q, et al. Psychosocial predictors of smoking among secondary school students in Henan, China. Health Educ Res. 2000;15(4):415-422.

31. DuongTran P. Sociocultural perceptions and patterns of cigarette and alcohol use among college students in Vietnam. Asian Social Work and Policy Review. 2008; 2(3):149-158.

32. Zhu BP, Liu M, Wang SQ, et al. Cigarette smoking among junior high school students in Beijing, China. Int J Epidemiol. 1992; 21(5):854-861.

33. Watson NA, Clarkson JP, Donovan RJ, et al. Filthy or fashionable? Young people's perceptions of smoking in the media.Health Edu Res. 2003; 18(5).

34. Mediaworks S: 'Bollywood': Victim or Ally? A WHO study on the portrayal of tobacco in Indian cinema. Geneva, Switzerland: World Health Organization and Tobacco Free Initiative. 2003. Available from: http:// www.who.int/tobacco/wntd/2003/en/bollywoodexesum.pdf 